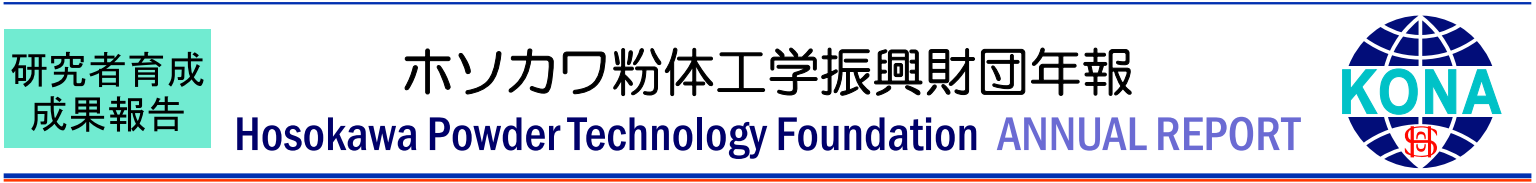

18503

\title{
ペロブスカイトナノ結晶のオストワルド熟成の解明 \\ Elucidation of Ostwald Ripening Process for Perovskite Nanocrystals
}

\author{
援助対象者 Scholarship Student: 梅本 和輝 Kazuki UMEMOTO \\ 梅本 和輝 \\ 山形大学大学院理工学研究科 博士課程後期 3 年 \\ Graduate School of Science and Engineering, Yamagata University, PhD Student (D3) \\ E-mail: tsr16867@st.yamagata-u.ac.jp
}

\begin{abstract}
研究指導者 Academic Leader：増原 陽人 Akito MASUHARA
教授, Professor

E-mail: masuhara@yz.yamagata-u.ac.jp
\end{abstract}

抄 録

ペロブスカイトナノ結晶は, 狭半值幅, 高量子収率等の優れた光学特性を有し, 広色域デイスプレ イの発光源として期待される。しかし，精緻なサイズ制御且つ発光波長を幅広く制御できるぺロブ スカイトナノ結晶の作製技術の確立は未開拓である。上記背景より，筆者等は，オストワルド熟成 を用いたペロブスカイトナノ結晶のサイズ微小化技術を提案し，本報告では，サイズ微小化に伴う 発光挙動の変化を解明した。

\section{ABSTRACT}

Perovskite nanocrystals (PeNCs) have superior optical properties like narrow half width and a high quantum yield and are expected as a photonic source for a wide color gamut display. However, precise controlling of the PeNC sizes which is capable to demonstrate the PL peaks in wide range has not been developed. From the above background, we have been proposing a down-sizing protocol preparing for the PeNCs using Ostwald ripening, and we elucidate the PL behavior from the down-sized PeNCs in this report.

成 果 の 概 要

\section{1. 緒言}

高度情報化社会の到来により，現在，遠隔治 療用ディスプレイや車載用デイスプレイ等の社 会ニーズに応える広色域ディスプレイの開発が
期待されている.ディスプレイの広色域化には, 発光色の高純度化が必須であり，これまで半導 体ナノ結晶を主流に, 様々な発光材料が研究開 発されてきた，近年では，太陽電池材料として 脚光をあびるハロゲン化鉛ペロブスカイト $\left(A M X_{3}, A=\mathrm{CH}_{3} \mathrm{NH}_{3}, \mathrm{Cs}, M=\mathrm{Pb}, \mathrm{Sn}, X=\mathrm{Cl}, \mathrm{Br}, \mathrm{I}\right)$ 
を数〜数十 $\mathrm{nm}$ まで微小化させたペロブスカイ トナノ結晶 $(\mathrm{PeNCs})$ が, 高い発光量子収率 $(\mathrm{PLQY}>90 \%)$, 狭半值幅 $(\mathrm{FWHM}<25 \mathrm{~nm})$, ハロゲン組成による可視光全域での発光波長の チューニング $\left(\lambda_{\mathrm{PL}}=405-730 \mathrm{~nm}\right)$ 等の優れた 発光特性を示すことが報告 (Zhang F. et al., 2015）されている。 そのため, PeNCsは, 発光 色の高純度化を達成できる発光材料として期待 されており, 現在, PeNCsの発光ダイオード (LEDs) への応用研究も意欲的に展開されてい る.

特に，上記ペロブスカイトは，イオン結晶で あり，温和な条件下にて溶液プロセスによる結 晶化が容易なため, 様々な作製手法による PeNCs の合成と発光特性の改善が可能である. これまでに, ホットインジェクション, Ligandassisted reprecipitation (LARP), 超音波合成, ミセル合成等が報告（Shamsi J. et al., 2019）さ れており, 高い発光特性とサイズ・形状の単分 散化が達成されている。 また，LARPをベース に反応温度 - 有機配位子の種類 - 添加量等の諸 条件によるPeNCs のサイズを精緻に制御する 試み（Polavarapu L. et al., 2017）もあるが，幅 広い波長領域且つ狭半值幅発光を示す PeNCs の作製は，未だ困難である。

一方, 申請者等は, 新たにオストワルド熟成 に着目し，独自性の高い PeNCsのサイズ制御 技術を提案してきた。オストワルド熟成 （Ostwald W.Z., 1900）とは, 粗大粒子が表面工
ネルギーの高い微小な粒子を吸収することで, さらに, その粒子サイズを増加させる結晶成長 プロセスとして，よく知られている。オストワ ルド熟成では, 一般に, 成長後の粗大粒子に焦 点を当てるが，筆者等は，ここで，敢えて溶解 する微粒子に着目した。即ち，オストワルド熟 成を促進させた後, 成長した粗大粒子を取り除 くことで, 溶解する微粒子のみを抽出でき, 最 終的に, PeNCs のサイズ微小化を達成できると 考えた。 具体的には, LARPを用いて, 予め調 整した PeNC 分散液を加温保持させることで, オストワルド熟成を促進させる。これにより， 粗大結晶を取り除いた後, PeNCs のサイズを $17 \mathrm{~nm}$ から $5 \mathrm{~nm}$ まで微小化させることに成功 した。また，PeNCsのサイズ微小化に伴う量子 サイズ効果の発現も明確に確認した. その結果, 単一化学組成からなる $\mathrm{MAPbBr}_{3} \mathrm{PeNCs} に て$, その発光波長を幅広く(517 nm から $456 \mathrm{~nm})$ 制御できることを見出してきた。

そこで本研究では，本実験系に打ける更なる オストワルド熟成の解明を目指し, サイズ微小 化させた PeNCs の光学特性を, より詳細に評 価することを目的とした。

\section{2. 実験手法と解析}

LARP とオストワルド熟成を組み合わせた手 法（図 1）により，次の手順にて, PeNCsのサ イズ微小化を達成した。臭化鉛 $(3.6 \mathrm{mg})$ と臭 化メチルアンモニウム（14.7 mg）を $N, N$ - ジメ

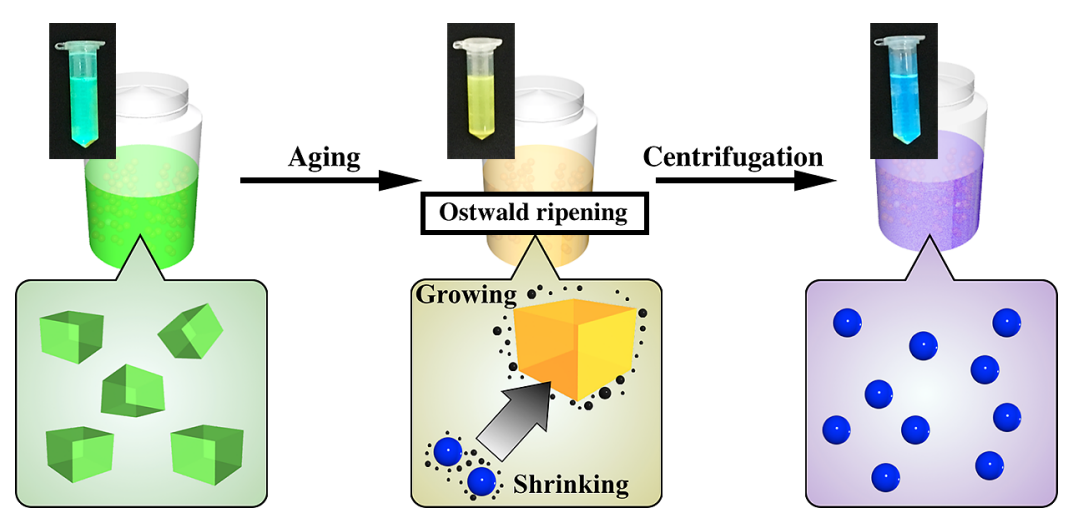

Fig. 1 A schematic illustration of the preparing protocol for precisely controlled PeNCs via Ostwald ripening. 
(a)

(b)
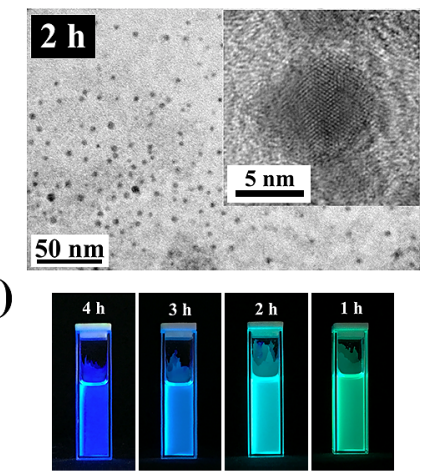

(c)

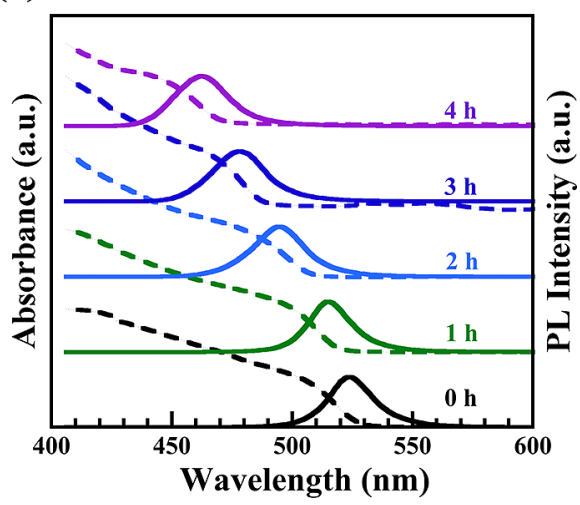

Fig. 2 (a) TEM image of the PeNCs aged for $2 \mathrm{~h}$. at $50^{\circ} \mathrm{C}$ after removing the coarse crystals. (b) Photographs of the PeNC supernatants aged for $1-4 \mathrm{~h}$ (after removing the coarse crystals). (c) Absorption and PL spectra of the PeNC suspension aged for $0-4 \mathrm{~h}$ at $50^{\circ} \mathrm{C}$.

チルホルムアミド $1 \mathrm{~mL}$ に溶かし, オクチルア ミン $20 \mu \mathrm{L}$ とオレイン酸 $0.5 \mathrm{~mL}$ を添加し, 前 駆体溶液を調整した，調整した溶液をぺロブス カイトの貧溶媒であるクロロホルムに注入した 後, 遠心分離し粗大粒子を取り除いた。また, 上澄みを $50^{\circ} \mathrm{C}$ で加温保持することで, オスト ワルド熟成を促した，その後, 再度, 遠心分離 を施し，粗大粒子を取り除くことで, PeNCsの サイズ微小化を達成した。

透過型電子顕微鏡により, PeNCs のサイズ・ 形状を評価した，また，種々の光学特性を吸収・ 発光分光光度計, 発光寿命- 絶対発光量子収率 測定装置を用いて評価した。

\section{3. 結果と考察}

本実験系では，貧溶媒としてょく用いられる トルエンに代わり, クロロホルムを用いる。 ク ロロホルムはトルエンに比べ, 比誘電率が高く, PeNCs を $50^{\circ} \mathrm{C}$ で一定時間, 加温保持すること で, PeNCs を不安定化 (PeNCs が微溶する) さ せ，オストワルド熟成を促進できる。実際に， 保持時間の増加による PeNCs のサイズ微小化 （表 1）とそれに伴う発光波長のブルーシフト （図2(c)）を確認した。特に, PeNCs を2 時間, 加温保持すると, その形状が, 四角形から球形 （図 2(a)）に変化し，サイズも $17 \mathrm{~nm}$ から $7 \mathrm{~nm}$ まで微小化した。また， $517 \mathrm{~nm}$ から $489 \mathrm{~nm}$ ま
Table 1 PL peaks, shifted energy, FWHM, and morphologies of the precisely controlled PeNCs via aging for $0-4 \mathrm{~h}$.

\begin{tabular}{|c|c|c|c|c|c|}
\hline $\begin{array}{c}\text { Aging } \\
\text { times/h }\end{array}$ & $\begin{array}{c}\lambda_{\mathrm{PL}} \\
/ \mathrm{nm}\end{array}$ & $\begin{array}{c}\Delta E \\
/ \mathrm{meV}\end{array}$ & $\begin{array}{c}\text { FWHM } \\
/ \mathrm{nm}\end{array}$ & $\begin{array}{c}\text { Size } \\
/ \mathrm{nm}\end{array}$ & Shape \\
\hline 0 & 517 & - & 21 & 16.7 & Square \\
\hline 1 & 508 & 42 & 20 & 12.1 & Square \\
\hline 2 & 489 & 95 & 25 & 7.2 & Spherical \\
\hline 3 & 472 & 91 & 26 & 6.1 & Spherical \\
\hline 4 & 456 & 92 & 26 & 5.3 & Spherical \\
\hline
\end{tabular}

で, 発光波長のブルーシフト確認した $\left(\Delta \lambda_{\mathrm{PL}}=\right.$ $28 \mathrm{~nm})$. さらに, PeNCsを 4 時間, 加温保持 すると, そのサイズは $5 \mathrm{~nm}$ まで微小化し, こ れは, $\mathrm{MAPbBr}_{3}$ の励起子ボーア半径である $3 \mathrm{~nm}$ (Sichert J.A. et al., 2015) とほぼ同程度の 大きさである。その発光波長は, $456 \mathrm{~nm}$ を示し, 加温保持前と比べ, 顕著にブルーシフト $\left(\Delta \lambda_{\mathrm{PL}}=61 \mathrm{~nm}\right)$ し, これは, 量子サイズ効果に よる大幅なバンドギャップエネルギーの増大を 意味している。ささらに，サイズ微小化させた $\mathrm{PeNCs}$ の発光は, いずれも狭半值幅（FWHM = 20-26 nm）を示し, PeNCs の均一性の高さを 示唆している.

サイズ微小化させた PeNCs の励起子再結合 ダイナミクスを解明するために, 時間分解 PL 寿命（図 3）と絶対 PL 量子収率（表 2) 測定 


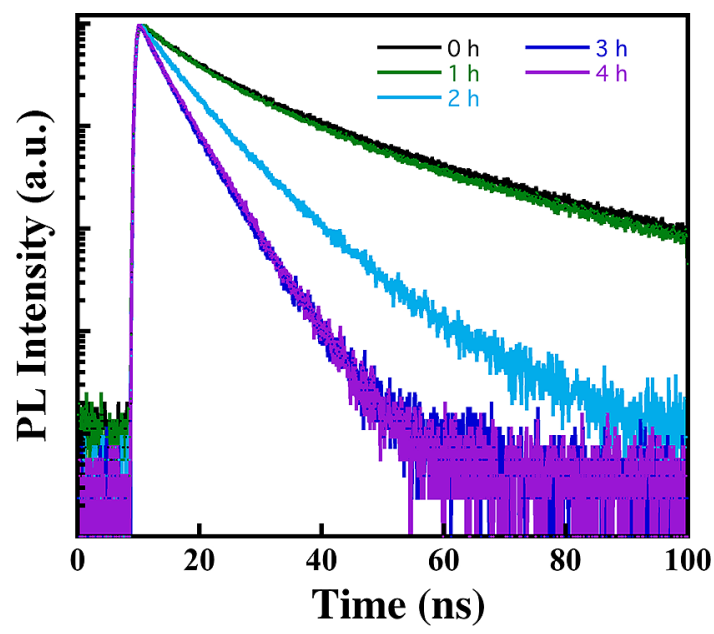

Fig. 3 Time-resolved PL decay curves of the precisely controlled PeNC supernatants via aging for $0-4 \mathrm{~h}$. at $50^{\circ} \mathrm{C}$.

を実施した。得られた全てのPL 減衰曲線は, 2 成分系でフィッティングでき, 保持時間の増 加に伴う発光寿命の短寿命化と発光量子収率拀 よび発光寿命の成分比の変動（図 3, 表 2）を 明確に確認した，特に，加温保持する前の $\mathrm{PeNCs}$ の発光寿命は, $32 \mathrm{~ns}$ と $10 \mathrm{~ns}$ を示すが, 3 時間以上, 加温保持すると, その発光寿命は, $5.1 \mathrm{~ns}$ と $2 \mathrm{~ns}$ まで短寿命化する。また, 発光量 子収率 (PLQY) も, 無輻射速度定数の増加に より，4 時間の加温保持で，その PLQY は $47 \%$ （表2）まで減少した。この PLQY の減少は, 長時間の加温保持により, PeNCs の表面に キャッピングしたオクチルアミン等の配位子の 脱離やサイズ微小化に伴う比表面積の増加等が 考えられるが, 今後, さらなる詳細な発光挙動 の解析が必要である.

\section{4. 結言}

本実験系におけるオストワルド熟成を，より 詳細に理解することを目的に, サイズ微小化さ せたPeNCsの光学特性の評価を行なった。そ の結果, PeNCs の加温保持時間の増加に伴う, サイズ微小化 $(17 \rightarrow 5 \mathrm{~nm})$ と明確な発光波長

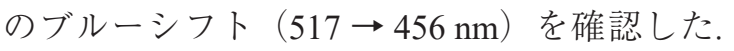

Table 2 PL Lifetimes, PLQYs, radiative decay rate, and non-radiative decay rates of the precisely controlled PeNCs supernatants via aging for $0-4 \mathrm{~h}$ at $50^{\circ} \mathrm{C}$.

\begin{tabular}{|c|c|c|c|c|}
\hline $\begin{array}{c}\text { Aging } \\
\text { times } / \mathrm{h}\end{array}$ & $\begin{array}{c}\tau_{\mathrm{Av}} \\
/ \mathrm{ns}\end{array}$ & $\begin{array}{c}\text { PLQY } \\
/ \%\end{array}$ & $\begin{array}{c}K_{\mathrm{r}} \\
10^{7} / \mathrm{s}^{-1}\end{array}$ & $\begin{array}{c}K_{\mathrm{nr}} \\
10^{7} / \mathrm{ns}^{-1}\end{array}$ \\
\hline 0 & 23.8 & 57 & 2.4 & 1.8 \\
\hline 1 & 22.4 & 58 & 2.6 & 1.9 \\
\hline 2 & 8.1 & 70 & 8.7 & 3.7 \\
\hline 3 & 4.8 & 64 & 13.4 & 7.5 \\
\hline 4 & 4.9 & 47 & 9.6 & 10.8 \\
\hline
\end{tabular}

また, 時間分解 PL 寿命と絶対 PL 量子収率測 定の結果， 3 時間以上の加温保持により，著し く，その PLQY が減少することが明らかになっ た。これは，キャッピングした配位子の脱離に よる表面欠陥増加等を示唆していると云える。

\section{参考文献}

Ostwald W., On the assumed isomerism of red and yellow mercury oxide and the surface-tension of solid bodies, Journal of Physical Chemistry B, 34 (1900) 495-503. https://doi.org/10.1515/zpch-1900-3431.

Polavarapu L., Nickel B., Feldmann J., Urban A.S., Advances in quantum-confined perovskite nanocrystals for optoelectronics, Advanced Energy Materials, 7 (2017) 1700267. https://doi.org/10.1002/aenm.201700267

Shamsi J., Urban A.S., Imran M., De Trizio L., Manna L., Metal halide perovskite nanocrystals: Synthesis, post-synthesis modifications, and their optical properties, Chemical Reviews, 119 (2019) 3296-3348. https://doi.org/10.1021/acs.chemrev.8b00644

Sichert J.A., Tong Y., Mutz N., Vollmer M., Fischer S., Milowska K.Z., García Cortadella R., Nickel B., Cardenas-Daw C., Stolarczyk J.K., Urban A.S., Feldmann J., Quantum size effect in organometal halide perovskite nanoplatelets, Nano Letters, 15 (2015) 6521-6527.

https://doi.org/10.1021/acs.nanolett.5b02985

Zhang F., Zhong H., Chen C., Wu X.-g., Hu X., Huang H., Han J., Zou B., Dong Y., Brightly luminescent and color-tunable colloidal $\mathrm{CH}_{3} \mathrm{NH}_{3} \mathrm{PbX}_{3}(\mathrm{X}=\mathrm{Br}, \mathrm{I}, \mathrm{Cl})$ quantum dots: Potential alternatives for display technology, ACS Nano, 9 (2015) 4533-4542. https://doi.org/10.1021/acsnano.5b01154 
外部発表成果

\section{論文発表}

1. Tezuka Y., Umemoto K., Takeda M., Takahashi Y., Ebe H., Enomoto J., Rodbuntum S., Nohara T., Fontecha D., Asakura S., Chiba T., Furis M.I., Yoshida T., Uji-i H., Masuhara A., Effects of alkylamine chain length on perovskite nanocrystals after washing and perovskite light-emitting diodes, Japanese Journal of Applied Physics, 59 (2019) SDDC04.

https://doi.org/10.7567/1347-4065/ab4ecd
口頭・ポスター発表

1. Umemoto K., Takeda M., Tezuka Y., Lyu B., Rodbuntum S., Chiba T., Asakura S., Masuhara A., "Separation of Mono-Dispersed $\mathrm{CH}_{3} \mathrm{NH}_{3} \mathrm{PbBr}_{3}$ Perovskite Nanocrystals via Ostwald Ripening", 16th International Conference on Nanosciences \& Nanotechnology (Thessaloniki, Greece, July 2-5, 2019) P1-1.

"Best Poster Presentation" was received. 